\title{
Semiempirical Calculation of the Rotational Barrier and Valence Force Constants in Fluorocarbonylsulfenyl Chloride
}

\author{
A. H. Jubert*, C. O. Della Védova**, E. L. Varetti ***, O. E. Piro***, \\ and P. J. Aymonino*** \\ Cátedra de Química Inorgánica, Facultad de Ciencias Exactas, Universidad Nacional de La Plata, \\ La Plata, R. Argentina \\ Z. Naturforsch. 38a, 61-63 (1983); received August 23, 1982

\begin{abstract}
The rotational barrier about the $\mathrm{C}-\mathrm{S}$ bond in fluorocarbonylsulfenyl chloride $[\mathrm{FC}(\mathrm{O}) \mathrm{SCl}]$ is investigated using the CNDO method. The results confirm the existence of planar cis and trans conformers and the higher stability of the latter, as suggested by previous vibrational results.

The valence force constants in $\mathrm{FC}(\mathrm{O}) \mathrm{SCl}$ were also calculated and the values obtained compare favourably with results from a previous normal coordinate calculation and with those of related compounds.
\end{abstract}

\section{Introduction}

The infrared spectra of gaseous fluorocarbonylsulfenyl chloride $[\mathrm{FC}(\mathrm{O}) \mathrm{SCl}]$ show that it exists as a conformational mixture as indicates by the existence of two $\mathrm{CO}$ stretching bands and the temperature dependence of their relative intensities $[1,2]$.

The barrier to rotation about formal single bonds in different types of molecules has been investigated very throughly by spectroscopic techniques [3]. In $\mathrm{FC}(\mathrm{O}) \mathrm{SCl}$ the rotational process of interest is the rotation about the $\mathrm{C}-\mathrm{S}$ bond. In this work we have investigated this process by a semiempirical quantum calculation using the $\mathrm{CNDO} / 2$ method [4]. Valence force constants were estimated from the CNDO data by a simple method derived from a point charge model for the chemical bond [5]. The present results are compared with results obtained previously by a normal coordinate analysis [1] and with those of related compounds.

\section{Computational Procedure}

Molecular wave functions of the different conformers were calculated using the $\mathrm{CNDO} / 2$ method

* Member of the Carrera del Investigador, CIC, Prov. de Buenos Aires.

** Predoctoral fellow of CONICET, R. Argentina.

*** Member of the Carrera del Investigador, CONICET, R. Argentina.

Reprint requests to A. H. Jubert, Cátedra de Química Inorgánica, Facultad de Ciencias Exactas, UNLP, 47 esq. 115, $1900 \mathrm{La}$ Plata, R. Argentina. employing the original parametrization given by Pople et al. [4].

As was already pointed out [1], no structural study of $\mathrm{FC}(\mathrm{O}) \mathrm{SCl}$ is still available but the molecular structure has been ascertained from the vibrational spectra and by comparison with related compounds.

A planar conformation should be expected as observed for methyl haloformate [6] and methyl thiofluoroformate ([7] and references therein). The planar models for the molecule are supported by the observed band envelopes in the IR spectrum of the gaseous substance [1]. A trans conformation of halogen atoms seems to be the most stable one as deduced from the band contour analysis of the most intense carbonyl band in the gas phase infrared spectrum and by comparison with related molecules. The proposed molecular geometry was used to calculate the separation between $\mathrm{P}$ and $\mathrm{R}$ branches of parallel bands [1]. The calculation was based in the following molecular parameters (in $\AA$ or angular degrees): $\mathrm{C}-\mathrm{F}: 1.37 ; \mathrm{C}=\mathrm{O}: 1.19 ; \mathrm{C}-\mathrm{S}$ : 1.76; OCS: 126; FCS: 110 (from a microwave study of methyl thiolfluoroformate [7]); $\mathrm{S}-\mathrm{Cl}: 2.01 ; \mathrm{CSCl}$ : 103 (from a microwave study of $\mathrm{SCl}_{2}$ [8]). (It is worth mentioning that such a value for the $\mathrm{CSCl}$ angle is compatible with a more stable trans conformation. This would not be the case if a smaller angle were assumed, for example $98.9^{\circ}$ by comparison with $\mathrm{CF}_{3} \mathrm{SCl}$ [9]). The results of such a calculation were practically coincident with the observed PR separations [1] and gave us an ap- 
proach to the best molecular geometry for the calculation.

The following three conformations were considered:

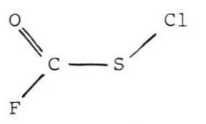

A $\varphi=0^{\circ}$, trans

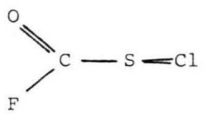

$\mathrm{B}$
The geometry of the conformers was found by minimizing the total energy with respect to the geometry variables defining the structure. This was done by interpolation between energies calculated for a number of specific geometries around the minimum (local) energy. With the optimized structural parameters, density and overlap matrices, total and bond energies and dipole moments for $\mathrm{A}, \mathrm{B}$ and $\mathrm{C}$ were determined.

The calculations were performed on a IBM 4331 computer with a QCPE program using STO as basis set. The calculations described were carried out with an extensively modified version of the CNDO/2 QCPE Program No 141 written by Pople and Doborch $[4 \mathrm{a}-\mathrm{c}]$ and completely documented by Pople and Beveridge [ $4 \mathrm{~d}]$. Intermediate numbers were carried in double precision for all molecular orbital calculations. The program was modified to suit local input-output requirements and to facilate the change of the dimension statements.

Calculations were also performed with $\mathrm{MINDO} / 3$ [10] and MNDO [11] using their standard forms, but in both cases the resulting optimized geometry was far apart from the proposed configuration and both methods failed in predicting the trans conformer as the most stable one. This confirms the importance of including in the calculation d-orbitals for heavy atoms.

The nature of the atoms in the studied molecule made it inconvenient to use a standard ab-initio procedure.

\section{Results and Discussion}

The conformational energies involved in the rotation of the $\mathrm{SCl}$ group around the $\mathrm{C}-\mathrm{S}$ bond were calculated for different values of the azimuthal angle $\varphi$ formed by the $\mathrm{S}-\mathrm{Cl}$ bond when rotated around the $z$ axis defined by the $\mathrm{C}-\mathrm{S}$ bond. All other atoms were considered fixed on the $x z$ plane.
The results confirm that the planar cis and trans configurations have the lowest energies and that the trans conformer is the more stable one. The predicted height of the rotational barrier is $4.39 \mathrm{kcal} \mathrm{mol}^{-1}$. The calculated energy difference between the conformers $\left(0.75 \mathrm{kcal} \mathrm{mol}^{-1}\right)$ is lower than the experimental value (ca. $2.0 \mathrm{kcal} \mathrm{mol}^{-1}$ [2]).

The CNDO calculation shows from the localized molecular orbitals that the lone pairs on the sulphur and chlorine atoms are more localized in the gauche form than in the planar conformations; thus it can be accepted that the origin of the barrier is the decrease in delocalization for the gauche conformer.

In the discussion of the barrier to rotation about the $\mathrm{C}-\mathrm{S}$ single bond it is expedient to study the changes in charge density and bond indices. The changes in charge densities caused by a cis-gauche rotation involve that the carbonyl oxygen and carbon atoms lose a considerable amount of negative and positive charge, respectively, in the gauche form. The carbonyl $\uparrow$ bond becomes less polarized and the bond index has its maximum value in the gauche form, at $\varphi=90^{\circ}$. The bond index of the $\mathrm{C}-\mathrm{S}$ bond in planar configurations is larger than in the gauche one, showing an increase of delocalization.

In spite of reports on the failure of the $\mathrm{CNDO} / 2$ method to predict correctly the most stable conformer in molecules showing some delocalization along the rotation axis [12-14], our results correctly predict that the trans conformer is more stable than the cis, although the value of the energy difference differs by a factor of three from experimental result [2].

Table 1. CNDO atomic charges and bond indices for $\mathrm{FC}(\mathrm{O}) \mathrm{SCl}$.

\begin{tabular}{|c|c|c|c|}
\hline & \multicolumn{3}{|c|}{ Conformation } \\
\hline & cis & gauche & trans \\
\hline \multicolumn{4}{|c|}{ Atomic charge } \\
\hline $\mathrm{C}$ & +0.4175 & +0.4058 & +0.4142 \\
\hline $\mathrm{O}$ & -0.2066 & -0.1818 & -0.2064 \\
\hline $\mathrm{F}$ & -0.1889 & -0.1918 & -0.1850 \\
\hline $\mathrm{S}$ & -0.0013 & -0.0058 & +0.0011 \\
\hline $\mathrm{Cl}$ & -0.0207 & -0.0264 & -0.0239 \\
\hline \multicolumn{4}{|c|}{ Bond index $\left(B_{\mathrm{AB}}\right)$} \\
\hline $\mathrm{C}=\mathrm{O}$ & 1.6698 & 1.6792 & 1.6717 \\
\hline$C-F$ & 0.9048 & 0.9062 & 0.9041 \\
\hline $\mathrm{C}-\mathrm{S}$ & 1.0036 & 0.9049 & 1.0242 \\
\hline $\mathrm{S}-\mathrm{Cl}$ & 1.5045 & 1.5032 & 1.5044 \\
\hline
\end{tabular}


Table 2. CNDO, stepwise coupling force constants for $\mathrm{FC}(\mathrm{O}) \mathrm{SCl}$ and force constants of related compounds.

\begin{tabular}{lcll}
\hline Bond & \multicolumn{2}{c}{$\begin{array}{l}f_{\mathrm{AB}} \text { from } \mathrm{FC}(\mathrm{O}) \mathrm{SCl} \\
\end{array}$} & $\begin{array}{l}f_{\mathrm{AB}} \text { from related } \\
\text { compounds }\end{array}$ \\
\cline { 2 - 3 } & $\begin{array}{l}\text { this } \\
\text { work }\end{array}$ & $\begin{array}{l}\text { stepwise } \\
\text { coupling [1] } \\
\text { force constants }\end{array}$ & \\
\hline $\mathrm{C}=\mathrm{O}$ & 15.4 & 13.10 & $15.2\left(\mathrm{COF}_{2}\right)^{\mathrm{a}}$ \\
$\mathrm{C}-\mathrm{F}$ & 5.7 & 5.03 & $13.7(\mathrm{COFCl})^{\mathrm{b}}$ \\
$\mathrm{C}-\mathrm{S}$ & 3.0 & 4.32 & $5.64\left(\mathrm{COFCl}^{\mathrm{b}}\right.$ \\
$\mathrm{S}-\mathrm{Cl}$ & 3.2 & 3.37 & $3.05\left(\mathrm{CF}_{3} \mathrm{SH}\right)^{\mathrm{c}}$ \\
\hline
\end{tabular}

a J. L. Brema and D. C. Moule, Spectr. Acta 28, 809 (1972).

b H. Oberhammer, J. Chem. Phys. 73, 4310 (1980).

c J. Borrajo, E. L. Varetti, and P. J. Aymonino, J. Mol. Struct. 29, 163 (1975).

d D. Bielefeldt and H. Willner, Spectr. Acta 36 A, 929 (1980).

e A. Ben Altabef, E. L. Varetti, and P. J. Aymonino, XV. Argentine Chemical Meeting, San Miguel de Tucumán 1980.

As mentioned above, the valence force constants were estimated with the expression [5]

$$
f_{\mathrm{AB}}=\left[\frac{Z_{\mathrm{A}}-2}{Z_{\mathrm{A}}}\right]\left[\frac{2 Z_{\mathrm{A}}-Q_{\mathrm{A}}}{R^{3}}\right]\left(8 B_{\mathrm{AB}}-q_{\mathrm{B}}\right),
$$

where $Z_{\mathrm{A}}=$ charge of atom $\mathrm{A}$ as used in the CNDO approximation, $Q_{\mathrm{A}}=$ gross charge on atom $\mathrm{A}, q_{\mathrm{B}}=$

[1] C. O. Della Védova, E. L. Varetti, and P. J. Aymonino, to be published.

[2] C. O. Della Védova, A. H. Jubert, E. L. Varetti, and P. J. Aymonino, to be published.

[3] W. J. Orville-Thomas, Internal Rotation in Molecules, John Wiley, London 1974.

[4] a) J. A. Pople, D. F. Santry, and G. A. Segal, J. Chem. Phys. 43, 5129 (1965). b) J. A. Pople and G. A. Segal, J. Chem. Phys. 44, 3289 (1966). c) J. A. Pople, D. F. Santry, and G. A. Segal, J. Chem. Phys. 43, 5136 (1965). d) J. A. Pople and D. L. Beveridge, Approximate Molecular Orbital Theory, McGraw Hill, New York 1970.

[5] W. Kosmus, Z. Naturforsch. 33 a, 1056 (1978).

[6] G. Williams, N. L. Owen, and J. Sheridan, Trans. Faraday Soc. 67, 922 (1961).

[7] W. Caminati and R. Meyer, J. Molec. Spectr. 90, 303 (1981).

[8] J. T. Murray, W. A. Little Jr., Q. Williams, and T. L. Weatherly, J. Chem. Phys. 65, 9851 (1976). net charge on atom $\mathrm{B}, R=$ bond distance, $B_{\mathrm{AB}}=$ bond index calculated from the Wiberg bond index [15]. For single bonds $B_{\mathrm{AB}}=W_{\mathrm{AB}}$, for double bonds $B_{\mathrm{AB}}=$ $W_{\mathrm{AB}}^{\sigma}+(1 / 2) 2^{1 / 2} W_{\mathrm{AB}}^{\leftarrow}$ and for triple bonds $B_{\mathrm{AB}}=$ $W_{\mathrm{AB}}^{\sigma}+(2 / 3) 2^{1 / 2} W_{\mathrm{AB}}^{\star}$.

The factor $\left(Z_{\mathrm{A}}-2\right) / Z_{\mathrm{A}}$, the so called atomic dipole contribution, occurs only when the atom $\mathrm{A}$ possesses lone electron pairs such as $\mathrm{P}, \mathrm{N}$, halogens, etc.

Our results are listed in Table 2 together with those obtained from a normal coordinate analysis previously performed [1] using a stepwise coupling method [16]. The comparison of internal force constants shows that the values obtained for $\mathrm{FC}(\mathrm{O}) \mathrm{SCl}$ are reasonable. The $\mathrm{C}=\mathrm{O}$ and $\mathrm{C}-\mathrm{F}$ stretching force constants are rather high whereas a rather low force constant results for the $\mathrm{C}-\mathrm{S}$ stretching indicating that the CNDO underestimates the conjugation effect.

\section{Acknowledgements}

To CONICET (Programa QUINOR), SUBCYT and CIC Provincia de Buenos Aires, Argentina, for support.

We thank Dr. Horacio Grimberg for useful discussions.

[9] H. Oberhammer, W. Gombler, and H. Willner, J. Mol. Struct. 70, 273 (1981).

[10] a) R. C. Bingham, M. J. S. Dewar, and D. H. Lo, J. Amer. Chem. Soc. 97, 1285 (1975). b) ibid 97, 1294 (1975). c) ibid 97, 1302 (1975). d) ibid 97, 1307 (1975). e) M. J. S. Dewar, D. H. Lo, and Ch. A. Ramsden, ibid 97, 1311 (1975).

[11] M. J. S. Dewar and W. Thiel, J. Amer. Chem. Soc. 99, 4899 (1977).

[12] C. Sieiro, P. Gonzalez-Diaz, and Y. S. Smeyers, J. Mol. Struct. 24, 345 (1975).

[13] O. Gropen and H. M. Seip, Chem. Phys. Lett. 11, 445 (1971).

[14] H. Perrin and J. Berges, J. Mol. Struct. 76, 299 (1981).

[15] K. B. Wiberg, Tetrahedron 24, 1083 (1968).

[16] H. J. Becher and R. Mattes, Spectrochim. Acta 23 A, 2449 (1967). 